В. В. Михайленко, I. В. Майкович, Т. А.Наухацька

\title{
МАТЕМАТИЧНА МОДЕЛЬ ДВАНАДЦЯТИПУЛЬСНОГО ПЕРЕТВОРЮВАЧА 3 ШЕСТИЗОННИМ РЕГУЛЮВАННЯМ НАПРУГИ
}

Анотація: У статті проведено аналіз електромагнітних процесів в електричних колах $з$ напівпровідниковими комутаторами. Створено математичну модель дванадцятипульсного напівпровідникового перетворювача 3 шестизонним регулюванням вихідної напруги для аналізу електромагнітних процесів у напівпровідникових перетворювачах 3 широтно-імпульсним регулюванням. Наведено графіки, що відображають електромагнітні процеси у електричних колах.

Ключові слова: напівпровідниковий перетворювач, шестизонне регулювання напруги, електромагнітні процеси.

\section{Вступ}

Завдяки широкому використанню напівпровідникових перетворювачів у електричних колах сучасних перетворювачів параметрів електроенергії значно ускладнюються задачі аналізу електромагнітних процесів. Найбільші ускладнення виникають при необхідності моделювання усталених і перехідних процесів у розгалужених колах змінної структури, в ланках з реактивними елементами якої виникають синусоїдні, постійні та імпульсні напруги. У роботах [1-4] показана доцільність використання структур напівпровідникових перетворювачів (НПП) 3 однократною модуляцією при побудові систем вторинного електропостачання для комплексів діагностики електромеханічних пристроїв із різноманітним видом вхідної енергії. У даній роботі проводиться аналіз аспекту використання тієї ж структури НПП в якості ланки високої частоти, що стосується побудови й аналізу перетворювачів для електромеханічних комплексів із широтно-імпульсним регулюванням (ШІР) постійної напруги при шестизонному керуванні.

Метою роботи є створення математичної моделі дванадцятипульсного напівпровідникового перетворювача з шестизонним регулюванням вихідної напруги.

\section{Аналіз електромагнітних процесів}

У данній роботі використано метод багатопараметричних модулюючих функцій [2], який передбачає попереднє представлення алгоритмічного рівняння перетворювача. При цьому прийнято такі припущення: вхідна енергетична мережа симетрична і їі внутрішній опір дорівнює нулю, транзистори і діоди інвертора випрямленої напруги (IBH) представляються ідеальними ключами, узгоджувальні трансформатори в кожній з зон регулювання вихідної напруги не мають втрат, а навантаження перетворювача має еквівалентний активно-індуктивний характер.

( В. В. Михайленко, I. В. Майкович, Т. А.Наухацька 
Структурна схема НПП показана на рисунку 1. На структурній схемі позначено: CM1 і СМ2 - блоки силових модуляторів фазних і лінійних напруг відповідно; ВB1 і ВВ2 - високочастотні випрямлячі фазних і лінійних напруг; СК - система керування і $\mathrm{H}$ - навантаження, яке має активно-індуктивний характер. Кожний з блоків СМ має у своєму складі випрямлячі та інвертори, навантажених на узгоджувальні трансформатори.

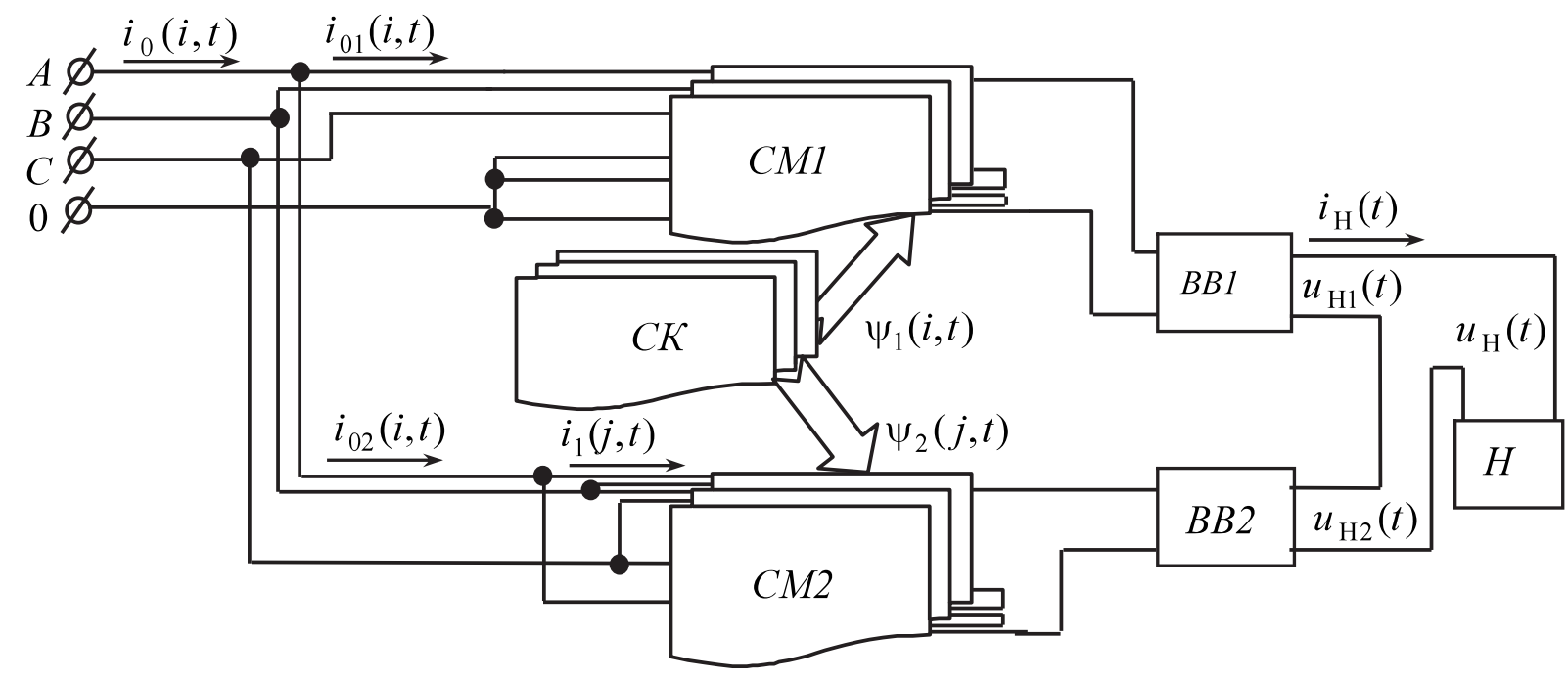

Puc. 1. Структурна схема перетворювача

Таким чином кожен СM має в своєму складі $\mathrm{N}$ IBH, де $\mathrm{N}$ - це число інверторів. Створення математичної моделі перетворювача передбачає розробку математичного забезпечення, спроможного провести аналіз відносно енергії, яка генерується, з урахуванням навантаження, енергії, яка споживається, а також енергіï, яка перетворюється в окремих ланках і в окремими елементами.

Алгоритмічне рівняння перетворювача записано у публікації [2]:

$$
u_{\mathrm{H}}(t)=\frac{1}{k_{\mathrm{T}}}\left(\sum_{n=1}^{N=3} \sum_{i=1}^{3} u_{11}(i, t) \phi_{1}(i, t) \psi_{1}(i, t) v_{1}(t)+\sum_{n=1}^{N=3} \sum_{j=1}^{3} u_{12}(j, t) \phi_{2}(j, t) \psi_{2}(j, t) v_{2}(t)\right) \text {, }
$$

де: $i=1,2,3$ i $j=1,2,3$ - номера фазних і лінійних напруг енергетичної мережі

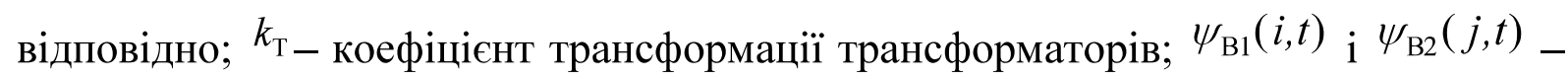
модулюючі функції, які співпадають за часом з фазними і лінійними напругами; $u_{11}(i, t)$ i $u_{12}(j, t)$ - миттеві значення лінійних напруг; $v_{1}(t)$ i $v_{2}(t)$ - еквівалентні модулюючі впливи $B B 1$ і $B B 2 . ; n=1,2,3, \cdots, N=3$ - номери зон регулювання вихідної напруги; $N=3-$ кількість IBH в кожному $\mathrm{CM}$; $\psi_{\mathrm{B} 1}(i, t)=\operatorname{sign}\left[\sin \left(\omega_{1} t-\varphi-\frac{(i-1) 2 \pi}{3}\right)\right]-$ модулюючі функції, які співпадають за 
Міжвідомчий науково-технічний збірник «Адаптивні системи автоматичного управління» № 1' (32) 2018

часом 3 положеням відповідних фазних напруг мережі живлення; $\psi_{\mathrm{B} 2}(j, t)=\operatorname{sign}\left[\sin \left(\omega_{1} t-\varphi+\frac{\pi}{6}-\frac{(j-1) 2 \pi}{3}\right)\right]-$ модулюючі функції, які співпадають за часом 3 положеням відповідних лінійних напруг мережі живлення; $u_{01}(i, t)=E_{m} \sin \left(\omega_{1} t-\varphi-\frac{(i-1) 2 \pi}{3}\right)-$ миттеві значення вхідних фазних напруг мережі живлення, $u_{02}(j, t)=E_{m} \sin \left(\omega_{1} t-\varphi+\frac{\pi}{6}-\frac{(j-1) 2 \pi}{3}\right)-$ миттеві значення вхідних фазних напруг мережі живлення, $E_{m}$ - амплітудне значення фазної напруги; $\omega_{1}=2 \pi f_{1}$ і $\varphi-$ відповідно кругова частота і початкова фаза напруги живлення; $\psi_{1}(i, t)$ - множина еквівалентних модулюючих впливів $\mathrm{j}-\mathrm{x} \mathrm{CM,} \psi_{2}(j, t)-$ множина еквівалентних модулюючих впливів j-х СМ.

Струм на навантаженні перетворювача знайдемо, як реакцію одноконтурного RL-ланцюга на дію напруги $u_{\mathrm{H}}(t)$

$$
i_{\mathrm{H}}(t) R+L \frac{d i_{\mathrm{H}}(t)}{d t}=u_{\mathrm{H}}(t),
$$

де: $R$ і $L$ - відповідно активний опір і індуктивність навантаження.

Рішення (2) відносно струму навантаження визначимо числовим методом за допомогою функції odesolve математичного процесора MATHCAD

$$
i_{\mathrm{H}}(t)=\operatorname{odesolve}(t, k, p,),
$$

де: $t$ - час; $k$ - часовий інтервал; $p$ - кількість точок на часовому інтервалі.

Діаграми струму навантаження в координатах вихідної напруги перетворювача, побудовані за (3) для шестизонного регулювання представлені на рисунку 2.

Фазні струми $i_{01}(i, t)$ знаходимо з виразу

$$
i_{01}(i, t)=\frac{\sum_{n=1}^{N=3} i_{\mathrm{H}}(t) \psi_{\mathrm{B} 1}(i, t) \psi_{1}(i, t) \nu_{1}(\mathrm{t})}{k_{\mathrm{T}}} .
$$

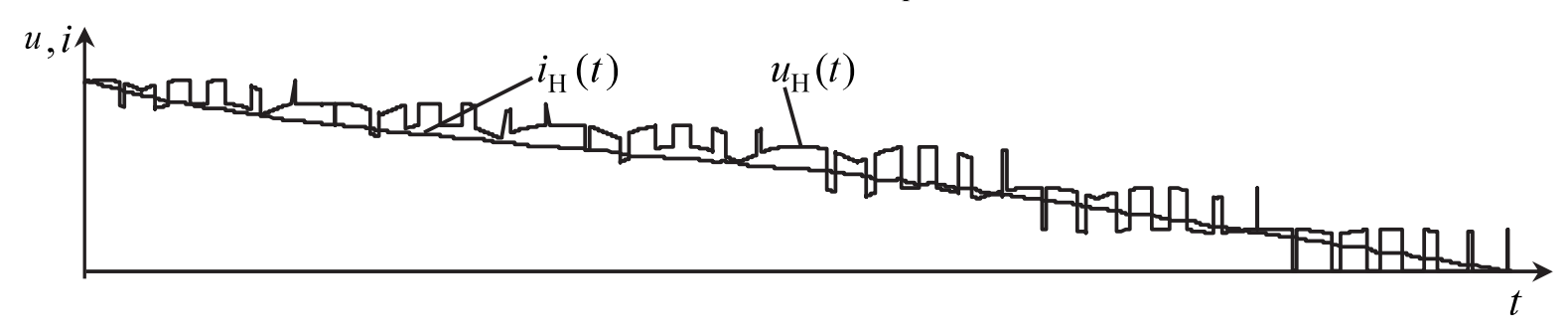

Puc. 2. Діаграми струму та напруги навантаження 
Лінійні струми $i_{12}(j, t)$ знаходимо з виразу виду

$$
i_{12}(j, t)=\frac{\sum_{n=1}^{N=3} i_{\mathrm{H}}(t) \psi_{\hat{\mathrm{A}} 2}(j, t) \psi_{2}(j, t) \nu_{2}(\mathrm{t})}{k_{\mathrm{T}}} .
$$

Фазні струми $i_{02}(i, t)$ знаходимо з співвідношень

$$
i_{02}(1, t)=i_{12}(1, t)-i_{12}(3, t) ; i_{02}(2, t)=i_{12}(2, t)-i_{12}(1, t) ; i_{02}(3, t)=i_{12}(3, t)-i_{12}(2, t) .
$$

Вхідні фазні струми енергетичної мережі у кожній $i$-й фазі знаходимо з виразу:

$$
i_{0}(i, t)=i_{01}(i, t)+i_{02}(i, t) .
$$

Діаграми вхідних фазних струмів перетворювача в координатах напруг енергетичної мережі, побудовані за (7), представлені на рисунку 3.
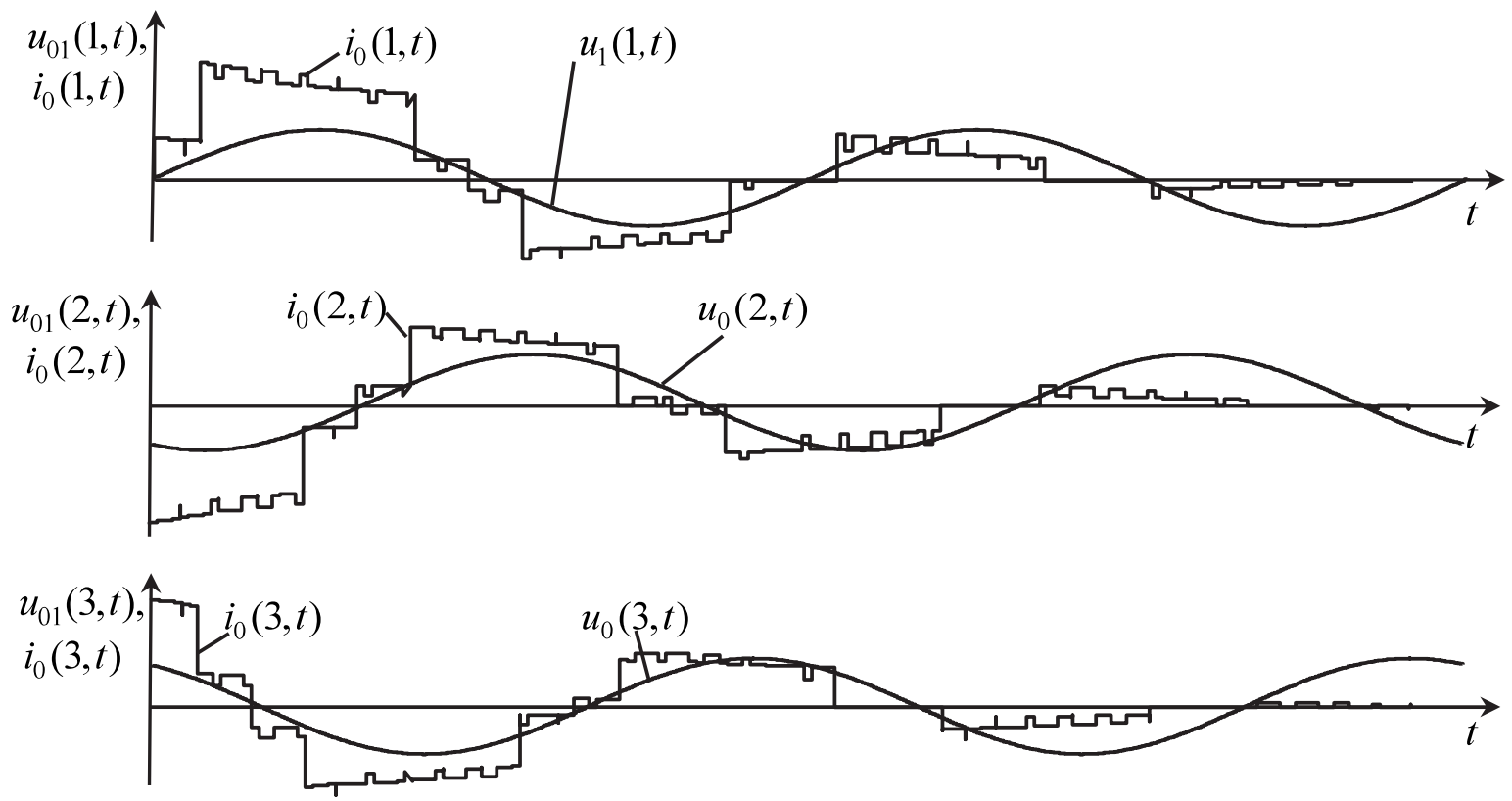

Puc. 3. Діаграми вхідних струмів $i$-х фаз мережі в координатах фазних напруг

\section{Висновки}

У данні роботі було виконано аналіз електромагнітних процесів в електричних колах 3 напівпровідниковими перетворювачами. Використовуючи метод багатопараметричних модулюючих функцій було знайдено струм i напругу навантаження, а також вхідні струми перетворювача. У роботі розвинуто метод багатопараметричних функцій в частині розробки нової математичної моделі з багатозонним регулюванням вихідної напруги та визначення модулюючих функцій для аналізу за підсистемними складовими структури електричних кіл з напівпровідниковими комутаторами.

Також формалізовано можна визначати алгоритми управління комутаторами в колах силових модуляторів фазних і лінійних напруг трифазної мережі 
електроживлення, що спрощує підвищення якості знакопостійних напруг у процесі формування та багатозонного регулювання вихідних синусоїдних i знакопостійних напруг. Використання багатопараметричних модулюючих функцій в математичних моделях електромагнітних процесів у електричних колах з напівпровідниковими комутаторами дозволяє формалізовано визначати струми в колах інверторів та інших напівпровідникових ланок кожного із силових модулів випрямлених напруг.

\section{Список використаних джерел}

1. Макаренко М.П. Математична модель перетворювача трифазної напруги в постійну напругу / М.П. Макаренко, В.В. Михайленко // Электроника и связь. 2002. - № 14. - С. 73-75.

2. Патент 20985. України. МПК Н02М 1/02. Модулятор випрямленої напруги / М. П. Макаренко, В. В. Михайленко, Заявник та власник патенту НТУУ "КПІ" - Завл. 18.09.2006, опубл. 15.02.2007. Бюл. № 2.

3. Макаренко М. П. Системний аналіз електромагнітних процесів у напівпровідникових перетворювачах електроенергії модуляційного типу / М. П Макаренко, В. І. Сенько, М. М. Юрченко - К. : НАН України, ІЕД, 2005. - 241 с.

4. Макаренко Н. П. Анализ электромагнитных процессов в двенадцатипульсном преобразователе с зонным регулированием выходного напряжения / Н. П. Макаренко, В. В. Михайленко, Н. Н. Юрченко // Вестник НТУ "Харьковский политехнический институт". "Проблемы автоматизированного электропривода. Теория и практика". - 2002. - Т. 1. - С. 233-234. 